\title{
Calcification intensity in planktonic Foraminifera reflects ambient conditions irrespective of environmental stress
}

\author{
M. F. G. Weinkauf ${ }^{1,2}$, T. Moller ${ }^{1}$, M. C. Koch ${ }^{3}$, and M. Kučera ${ }^{2}$ \\ ${ }^{1}$ Eberhard Karls Universität, Mathematisch-Naturwissenschaftliche Fakultät, Fachbereich Geowissenschaften, \\ Hölderlinstraße 12, 72074 Tübingen, Germany \\ ${ }^{2}$ MARUM, Leobener Straße, 28359 Bremen, Germany \\ ${ }^{3}$ Johann Wolfgang Goethe-Universität, Institut für Geowissenschaften, Facheinheit Paläontologie, Altenhöferallee 1, \\ 60438 Frankfurt am Main, Germany \\ Correspondence to: M. F. G. Weinkauf (mweinkauf@marum.de)
}

Received: 18 June 2013 - Published in Biogeosciences Discuss.: 8 July 2013

Revised: 6 September 2013 - Accepted: 16 September 2013 - Published: 23 October 2013

\begin{abstract}
Planktonic Foraminifera are important marine calcifiers, and the ongoing change in the oceanic carbon system makes it essential to understand the influence of environmental factors on the biomineralization of their shells. The amount of calcite deposited by planktonic Foraminifera during calcification has been hypothesized to reflect a range of environmental factors. However, it has never been assessed whether their calcification only passively responds to the conditions of the ambient seawater or whether it reflects changes in resource allocation due to physiological stress. To disentangle these two end-member scenarios, an experiment is required where the two processes are separated. A natural analogue to such an experiment occurred during the deposition of the Mediterranean sapropels, where large changes in surface water composition and stratification at the onset of the sapropel deposition were decoupled from local extinctions of planktonic Foraminifera species. We took advantage of this natural experiment and investigated the reaction of calcification intensity, expressed as mean area density (MAD), of four species of planktonic Foraminifera to changing conditions during the onset of Sapropel S5 (126-121 ka) in a sediment core from the Levantine Basin. We observed a significant relationship between MAD and surface water properties, as reflected by stable isotopes in the calcite of Foraminifera shells, but we failed to observe any reaction of calcification intensity on ecological stress during times of decreasing abundance culminating in local extinction. The reaction of calcification intensity to surface water perturbation at the onset of the sapropel was observed only
\end{abstract}

in surface-dwelling species, but all species calcified more strongly prior to the sapropel deposition and less strongly within the sapropel than at similar conditions during the present-day. These results indicate that the high-salinity environment of the glacial Mediterranean Sea prior to sapropel deposition induced a more intense calcification, whereas the freshwater injection to the surface waters associated with sapropel deposition inhibited calcification. The results are robust to changes in carbonate preservation and collectively imply that changes in normalized shell weight in planktonic Foraminifera should reflect mainly abiotic forcing.

\section{Introduction}

The amount of calcite present in a planktonic foraminifer shell at a certain time in relation to its size, hereafter referred to as calcification intensity, has been suggested to reflect various physical and chemical properties of the ambient seawater that affect the inorganic precipitation of calcite. In contrast to calcification rate, calcification intensity is here used as a measure of calcification independent of the time over which the calcification took place. Decreased shell weight of Foraminifera has been interpreted as resulting from ocean acidification and decreased $\mathrm{CO}_{3}^{2-}$ content of the seawater (Lohmann, 1995; Broecker and Clark, 2001). Therefore, in theory, a reaction of the calcification intensity of Foraminifera on ocean acidification resulting from 
anthropogenic atmospheric $\mathrm{CO}_{2}$, could severely influence the oceanic carbon cycle.

On geological timescales a relationship between Foraminifera calcification and the ocean carbonate system has been reported in Globigerina bulloides from a sediment core record in the North Atlantic by Barker and Elderfield (2002). The existence of a relationship between carbonate ion concentration and calcification intensity has been confirmed in laboratory culturing studies (Bijma et al., 1999; Lombard et al., 2010). Similarly, observations of shell thinning of planktonic Foraminifera in the Arabian Sea and Southern Ocean have been interpreted as a reaction of these organisms to anthropogenic carbon sequestration in the ocean (de Moel et al., 2009; Moy et al., 2009). However, a subsequent study of plankton material from the Arabian Sea by Beer et al. (2010b) revealed that the relationship between calcification intensity and carbonate ion concentration is not straightforward and may be species-specific, whereas Aldridge et al. (2012) identified phosphate concentration as the strongest determinant of calcification intensity in G. bulloides from North Atlantic plankton samples. Marshall et al. (2013) suggested the $\mathrm{CO}_{3}^{2-}$ content of the seawater to be the main influential factor on the calcification intensity of Globigerinoides ruber and Globigerinoides sacculifer on the basis of trap samples from the Cariaco Basin (Venezuela). However, since temperature was used to calculate the $\mathrm{CO}_{3}^{2-}$ values, the two variables were not independent. For this reason, the authors could not exclude the possibility that ambient temperature played an important role in mediating this relationship. All three studies provided evidence against the hypothesis by de Villiers (2004), that calcification intensity reflects optimum growth conditions, whereas Manno et al. (2012) showed that ambient temperature modulates the effect of changes in carbonate chemistry on calcification in Arctic Neogloboquadrina pachyderma.

Fundamentally, factors which are likely to control calcification intensity in planktonic Foraminifera depend on the degree to which the biomineralization process is coupled to physiological processes in the cell. Studies searching for candidate environmental factors affecting calcification assume that the biomineralization mimics inorganic precipitation. However, it is possible that biomineralization in Foraminifera could participate in a trade-off in the allocation of resources between biomass and biomineral. The existence of such trade-off is implied by the hypothesis of de Villiers (2004), which suggests that populations inhabiting environments, where all environmental parameters are close to the optimum of a species, are characterized not only by peakproductivity but also by highest calcification intensities in that species. This is consistent with the observation that size in planktonic Foraminifera reflects optimum growth conditions (Schmidt et al., 2004). Considering the seemingly contradictory results of existing studies on calcification intensity in planktonic Foraminifera, it appears that the process should be considered at a more fundamental level. Specifically, it re- mains to be established whether calcification intensity simply tracks the conditions of the ambient seawater or whether it reflects a physiological stress reaction of the organism at an appropriate ecological timescale.

Therefore, prior to further work attempting to isolate abiotic factors responsible for differences in calcification intensity in planktonic Foraminifera, the effect of environmental stress on this process has to be characterized. Environmental stress is here defined as the sum of physical, chemical, and biological factors influencing the productivity of a species. Provided growth and calcification are linked by a trade-off in resource allocation, then if environmental stress affects the productivity of a species, it could conceivably play a role for its calcification. Whereas it is difficult to disentangle individual aspects of environmental stress, its net result is easily quantifiable in terms of changes in the biomass of the studied species or population. This quantity is indirectly preserved in the fossil record, making it possible, in principle, to quantify how fossil populations were affected by stress. What is more, unlike the present-day situation, the fossil record allows investigating the effects of environmental stress resulting in a range of a priori known outcomes for the stressed population, including its total demise.

The amount of calcite preserved in fossil Foraminifera can be strongly influenced by post-mortem diagenetic processes. In order to circumvent this complication, the optimal setting to study calcification in the fossil record should be such where oversaturation of the entire water column with respect to carbonate can be demonstrated throughout the target time interval. The Eastern Mediterranean Sea is separated from the Western Mediterranean by the Sicilian Sill and Malta Sill (Wüst, 1961). Due to high evaporation rates in summer, surface ocean salinities can reach values larger than $39 \%$ in the eastern Levantine Basin (Wüst, 1961), making the water column highly oversaturated with respect to calcite (Schneider et al., 2007).

In addition, the Eastern Mediterranean is strongly influenced both by changes in monsoon intensity that alter freshwater input via the Nile, and changes in mid/high latitude climate patterns. Due to its small size and high sensitivity to hydrological processes, the basin amplifies environmental response to climate change (Rohling et al., 2002, 2009), and therefore offers an excellent opportunity to study the reaction of indigenous marine organisms on stress.

Here we take advantage of the unique environmental setting of the Eastern Mediterranean to study the response of calcification intensity in four species of planktonic Foraminifera to the environmental perturbation that led to the deposition of Sapropel S5 (Rohling et al., 2002). The environmental change associated with this perturbation induced a sequence of local extinctions and re-colonizations by planktonic Foraminifera species that can be tracked throughout the whole Eastern Mediterranean (Cane et al., 2002) (Fig. 1). The sapropel deposition reflects an abrupt environmental change leading to enhanced surface stratification and 


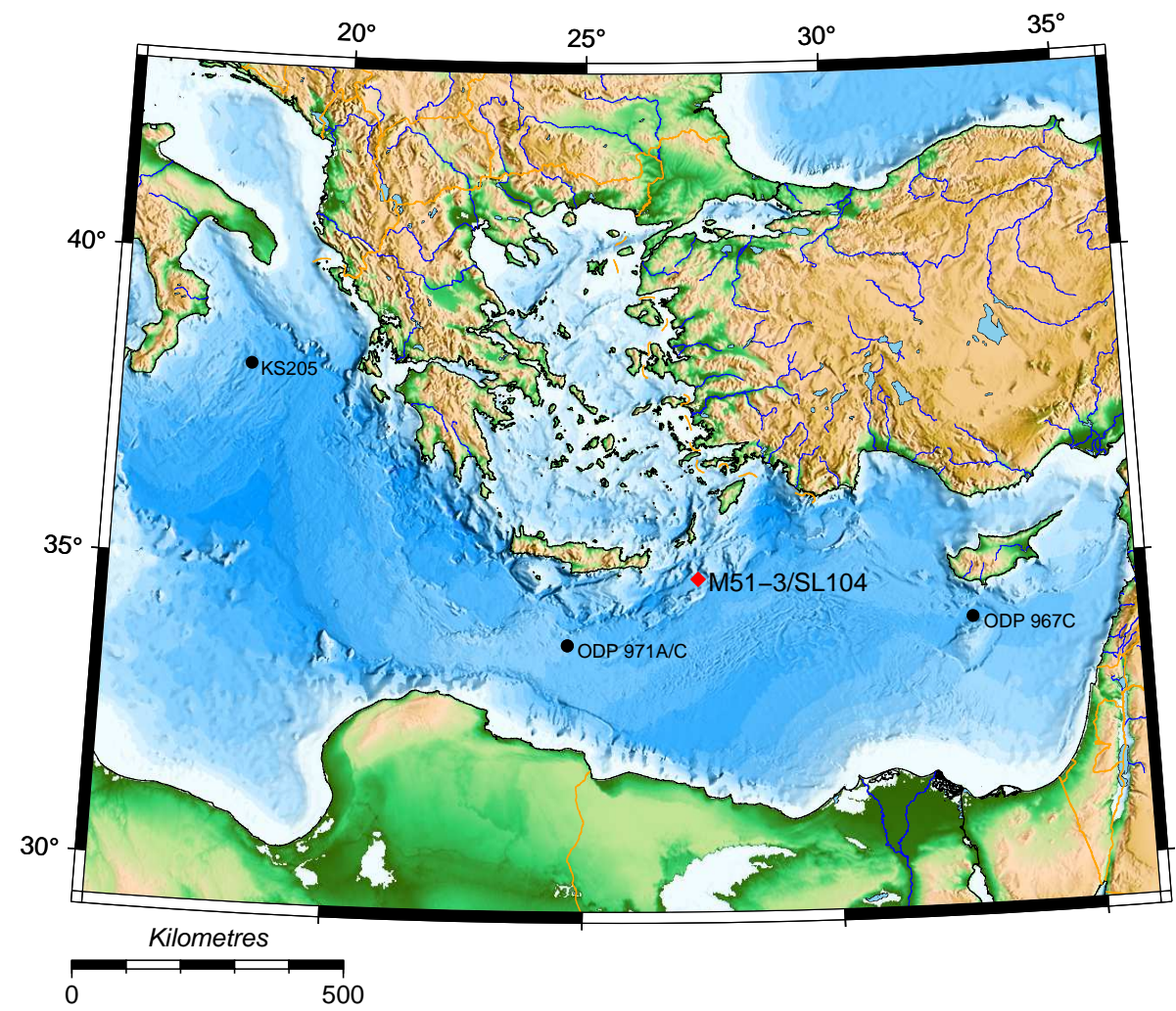

Fig. 1. Position of core M51-3/SL104 (red) in the Pliny Trench about $100 \mathrm{~km}$ east-southeast of Crete, as well as the position of the four other main cores (black), where the local extinction sequence of planktonic foraminifer species across Sapropel S5 has been established (Cane et al., 2002).

stagnation of the water column (Rossignol-Strick et al., 1982; Rossignol-Strick, 1983; Myers et al., 1998; Rohling et al., 2000). It is reflected in a drop in oxygen and carbon stable isotope values of planktonic Foraminifera at the onset of sapropel deposition, recording enhanced freshwater discharge from Africa (Williams et al., 1978).

Our hypothesis is that there are two possible modes of reaction of Foraminifera calcification intensity to the events surrounding the onset of Sapropel S5 deposition: (a) longterm ecological-scale reactions, due to the persistent environmental change associated with the onset of the sapropel, and (b) short-term physiological-scale effects, associated with the terminal environmental stress leading to local extinction of the species. Point (a) can be further divided into the hypotheses that there is either an influence (a1) of the environmental change itself (abiotic) or (a2) of the environmental stress associated with such a change (biotic) on the calcification intensity of planktonic Foraminifera.

Using palaeontological data extracted from the sediment record, instead of samples taken in recent environments or laboratory cultures, allows us to observe the reaction of natural communities that were exposed to natural levels of environmental stress over genuine ecological timescales. Furthermore the outcome of the environmental stress (i.e. local extinction events) is known, since the events took place in the past, whereas in recent environments the ultimate impact of the stressor on the community (e.g. adaptation, extinction) is unknown. Those advantages, however, come at the cost of not being able to exactly constrain the main stressor(s).

\section{Material and methods}

\subsection{Choice of species}

In order to characterize the reaction of calcification intensity across a spectrum of ecological preferences, habitats, and multiple extinction events, four species of planktonic Foraminifera were selected in this study. Globigerinoides ruber (pink) is a symbiont-bearing species and a strict shallow dweller with a main depth habitat at present of about $20 \mathrm{~m}$ in the Eastern Mediterranean (Pujol and Vergnaud Grazzini, 1995). The same depth habitat has been inferred for this species by Rohling et al. (2004) during the deposition of Sapropel S5. Aurahs et al. (2011) have shown that at present, Globigerinoides ruber (pink) represents a single genetic type of the Globigerinoides ruber $\mathrm{s}$. str. group. Thus the derived weight data are unlikely to be influenced by changes in species ecology or by the presence of multiple cryptic 
species with different calcification behaviour. This species appears in the Eastern Mediterranean shortly before the onset of Sapropel S5 deposition and remains in the basin at low relative abundances throughout the sapropel interval (Cane et al., 2002).

In order to observe a reaction in a shallow dwelling symbiont-bearing species to ecological stress, Orbulina universa was chosen, because this species exhibits two local extinctions across the studied interval of which at least one is observed basin-wide (Cane et al., 2002). This species has at present a shallow dwelling depth of 20-100 $\mathrm{m}$ in the Mediterranean (Pujol and Vergnaud Grazzini, 1995), and Rohling et al. (2004) interpret isotopic signatures in this species as indicative of growth in the summer mixed layer during Sapropel S5. Unlike G. ruber (pink), Orbulina universa shows a higher degree of cryptic speciation with several known genotypes. Thus, although until now only one genotype of $O$. universa has been reported in the Mediterranean (de Vargas et al., 1999), it cannot be excluded that the derived calcification intensities during the Sapropel S5 were affected by genetic diversity.

In order to extend the observations to deep dwelling species and replicate a response of a species to local extinctions, the species Globorotalia inflata and Globorotalia scitula have also been studied. Both species show a prominent local extinction at the onset of the Sapropel S5 deposition (Cane et al., 2002). Globorotalia inflata is an asymbiotic species dwelling slightly deeper than $O$. universa. Though its main habitat lies above $100 \mathrm{~m}$, it can be found alive at depths up to $700 \mathrm{~m}$ (Pujol and Vergnaud Grazzini, 1995; van Raden et al., 2011). It has been interpreted to dwell primarily within the winter mixed layer during the deposition of Sapropel S5 (Rohling et al., 2004). The entire Northern Hemisphere population of this species appears to represent a single genetic type (Morard et al., 2011). In contrast, the asymbiotic $G$. scitula is considered as a deep dwelling species. It is rare in the Mediterranean Sea at present (Pujol and Vergnaud Grazzini (1995) recorded peak abundances of only 9 specimens $/ 1000 \mathrm{~m}^{3}$ of filtered seawater) but analyses in the Atlantic Ocean show that G. scitula is most abundant between 200 and $500 \mathrm{~m}$ water depth in the Azores region (Schiebel et al., 2002). Rohling et al. (2004) reconstructed a dwelling depth corresponding to the intermediate waters in the Mediterranean, below the summer thermocline, for the time interval during which Sapropel S5 was deposited. The genetic diversity in G. scitula has not been studied, yet.

By including the four species in the analysis, our data set can be expected to record the reaction of calcification intensity on both the environmental and biotic forcing across multiple species and timescales of centuries to thousands of years.

\subsection{Sample processing and environmental data}

For this study a portion of gravity core M51-3/SL104 (Hemleben et al., 2003), taken in the Pliny Trench southeast of Crete in the Eastern Mediterranean Sea, was used (Fig. 1). This core contains an exceptionally thick and wellpreserved Sapropel S5, which is considered to have been deposited shortly after the Eemian Insolation Maximum (c. 126-121 ka) (Moller et al., 2012). Using a combination of event-based stratigraphy following Cane et al. (2002) with layer counting in the laminated part of the S5 sapropel, Moller (2012) showed that the major part of the studied section at the onset of Sapropel S5 in the studied core recorded an even sedimentation rate of about $4.8 \mathrm{~cm} \mathrm{kyr}^{-1}$. An abrupt change in the sedimentation rate occurred at $437.2 \mathrm{~cm}$ (Fig. 2). This age model is adopted in this study, but for our purposes, the absolute dating is left out, and we report ages relative to the onset of the sapropel.

Across the studied interval, the core was sampled in threemillimetre intervals, which yields a sample resolution of about $60-70 \mathrm{yr}$ in the majority of that section and approximately $11 \mathrm{yr}$ in the topmost $6 \mathrm{~cm}$. Samples were washed over a $63 \mu \mathrm{m}$ screen and dry-sieved, and only the fractions $\geq 150 \mu \mathrm{m}$ were used for this study. For this study, 70 samples from a section of the core have been selected to cover the onset of Sapropel S5, as well as local extinctions of the studied species within the early part of the sapropel interval (Fig. 2). Specimens for weight analysis have been picked from representative aliquots of the sample. In the majority of the cases, the entire sample has been used (Table S1).

A total of 2025 specimens of $O$. universa were picked from samples $1-70(455.5-434.8 \mathrm{~cm})$. This interval covers two local extinctions of the species, one in sample 44, after which the community was rapidly re-established, and one in sample 70, after which the species was absent from the sediment record for at least $240 \mathrm{yr}$. Of G. scitula $1290 \mathrm{spec}-$ imens were picked from samples 1-29 (455.5-447.1 cm), covering an interval until the prominent local extinction from sample 29 to 30 , after which the species is absent in the core for at least $360 \mathrm{yr}$. Globorotalia inflata shows a prominent local extinction after sample 31, after which the species remained virtually absent for the remainder of the sapropel. From that interval $(455.5-446.5 \mathrm{~cm}) 4129$ specimens of $G$. inflata were picked for analyses. A total of 243 specimens of $G$. ruber (pink) were picked from a narrow size fraction of 180-212 $\mu \mathrm{m}$ from samples 23-59 (448.9-438.1 cm), after the species re-invaded the Eastern Mediterranean.

The transition from sample 29 to $30(446.95 \mathrm{~cm})$ marks the onset of the sapropel, thus $G$. scitula became extinct shortly before the onset of the sapropel and $G$. inflata immediately afterwards, whereas $O$. universa survived for about $4000 \mathrm{yr}$ after onset of the sapropel (with the exception of sample 44) and $G$. ruber (pink) is hardly present before the sapropel onset at all. Relative abundances of the species were determined from assemblage counts, using 12.5-100 per cent of 


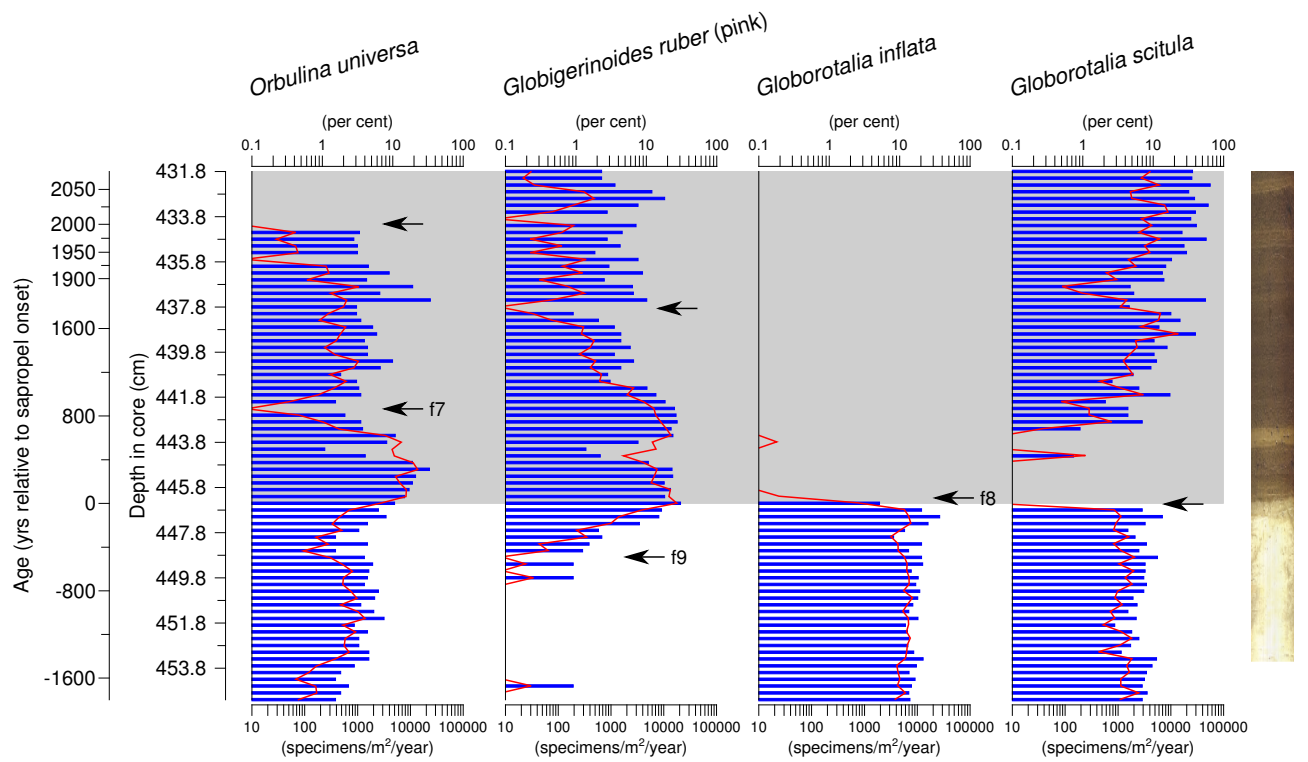

Fig. 2. Abundances of the investigated species of planktonic Foraminifera across the onset of Sapropel S5 in core M51-3/SL104, expressed as accumulation rates (blue bars) and relative abundances (red lines). Bioevents that have been used in this study are highlighted with arrows. Labelled arrows refer to bioevents (local extinction of O. universa and G. inflata, and occurrence of G. ruber (pink) in "detectable quantities"), that have been used by Cane et al. (2002, Table 2) to construct the Eastern Mediterranean biostratigraphy for Sapropel S5. The grey shaded area represents the extent of the sapropel. A core photograph is provided for comparison. Ages are given in years relative to sapropel onset. Note that $O$. universa shows no local extinction at $435.7 \mathrm{~cm}$, it only occurs in such small abundances that it was not detected in the split used for abundance reconstructions.

the sample volume (divided with a microsplitter, Table S1); these counts were used to determine absolute abundances, assuming constant sample volume. The relative abundances are considered a proxy for the reproductive success of a species relative to the other species in the planktonic Foraminifera community, and thus provide information about the competitiveness of the species. The absolute abundances could be recalculated to accumulation rates (specimens $\mathrm{m}^{-2} \mathrm{yr}^{-1}$ ) on the basis of the age model, generating a proxy for species productivity, and thus represent a measure of absolute reproductive success of a species.

For the reconstruction of the hydrological regime, oxygen and carbon stable isotope ratios (VPDB standard) were measured in specimens of Globigerinoides ruber (white) taken from the narrow size fraction of $250-315 \mu \mathrm{m}$.

\subsection{Area density}

The mean area density (MAD) was determined by weighing the shells using a Mettler Toledo UMX 2 microbalance, and a Sartorius SE 2 for $G$. ruber (pink) (accuracy $0.1 \mu \mathrm{g}$ for both scales), following procedures for determining the sizenormalized weight measurements suggested by Beer et al. (2010a) and Marshall et al. (2013). Shells for weighing were selected by first narrowing the possible size distribution of specimens by means of sieving. For $O$. univers $a$ the fraction $425-500 \mu \mathrm{m}$, for G. scitula and G.inflata the 150-200 $\mu \mathrm{m}$ size-fraction, and for $G$. ruber (pink) the $180-212 \mu \mathrm{m}$ size- fraction was used. All those fractions were chosen as to fall into the peak abundance size of the respective species as best as was possible. The thus selected specimens were cleaned by sonication and dried in a compartment dryer. After drying, specimens were transferred into microslides and left to equilibrate with air moisture for at least $24 \mathrm{~h}$. The specimens were subsequently picked with a needle, discarding all damaged individuals and specimens which showed remains of sediment filling. This process yielded 239 specimens of $O$. universa, 743 specimens of $G$. scitula, 462 specimens of $G$. inflata, and 166 specimens of $G$. ruber (pink) that were suitable for weighing. For the weighing process several shells were placed together in a tin weighing boat and weighed together repeatedly (10-20 times). Following Beer et al. (2010a) we aimed to weigh at least six specimens of Orbulina universa, and ten specimens of Globorotalia scitula, Globorotalia inflata, and Globigerinoides ruber (pink), respectively, per sample. After weighing, specimens were mounted on glass slides, using double-sided adhesive tape, photographed with a Leica Z16 stereomicroscope, and their cross-sectional area was measured using either the ImagePro ${ }^{\circledR}$ Plus v. 6.0 software (Media Cybernetics, Inc., 2006) or FIJI v. 1.47 (Schindelin et al., 2012). For each of the weighed samples, the mean area density (MAD) was determined as the mean measured weight, divided by the number of specimens weighed, normalized for the mean size of the weighed 
specimens (Eq. 1).

$\mathrm{MAD}=\frac{W / n}{S}$

where $W$ is the total weight of all specimens $n$ weighed together and $S$ is the mean cross-sectional area of those specimens.

Normalizing the weights for the cross-sectional area potentially introduces a certain error, because shell weight is primarily dependent on shell volume. However, assuming that the form of specimens of the same species remains similar, the resulting error can be considered very small, since shell volume and its cross-sectional area (assuming the same viewpoint was used in all images) are directly proportional. The normalization to area makes comparisons of MAD values among different species impossible. For that purpose we therefore normalized the data to their modern reference samples before comparison (compare Sect. 2.5).

Since the applied weighing procedure provided only one mean weight value per sample, instead of several individual values, confidence intervals for weight measurements could not be calculated by common approaches. To overcome that problem, confidence intervals were estimated by random resampling manually implemented in R v. 2.13.0 (R Development Core Team, 2011). For each investigated species one sample that yielded a relatively large number of weighable specimens was chosen. From that sample, six (Orbulina universa) or ten specimens (Globorotalia scitula, Globorotalia inflata, and Globigerinoides ruber (pink)), were randomly picked, weighed together, and then the MAD for that random sample was calculated as described in Eq. (1). The specimens were then put back and the whole procedure was repeated 29 times, yielding 30 partial values for the MAD of 30 random subsamples representative for the variability of the population. Since those partial values were completely random they can be considered to represent individual weights of 30 hypothetical specimens. In the next step, $N$ values from that pool of 30 partial values were randomly chosen (with replacement) and their mean was calculated - this procedure was repeated 2000 times per $N$, for all observed $n$ of the respective species. For each of the random replication sets the 0.025 and 0.975 quantiles were calculated according to the $\hat{Q}_{8}(p)$ definition recommended by Hyndman and Fan (1996). In that way for each observed sample size $n$ a corresponding $95 \%$ confidence interval for the MAD was approximated for each species. Since the confidence intervals were estimated in this way, the variability of the data could not easily be considered when investigating the relationship between the MAD and other parameters. This problem was dealt with by another randomization test, in which MAD values of the individual samples were randomly chosen from within the range of the $95 \%$ confidence interval. After 5000 reruns the mean of the test statistics was calculated and compared to the test statistics of the original data. Those mean values are marked with a bar hereafter, as opposed to the unmarked statistics of the original measurement values.

Orbulina universa is known to consist of multiple cryptic species, so the observed signal could in principle be influenced by a non-constant mixing ratio of different genotypes in the samples. To test for that possibility, specimens of $O$. universa from four selected depths were weighed individually in tin weighing boats (weighing was repeated six times per specimen, and then the mean value was calculated), and similar to the calculation of the MAD the obtained weight was then normalized for the size (cross-sectional area) of that specimen. This provided data sets with several values per depth level. Should any observed signal be the result of a changing genotype composition in the assemblage, we would assume to see the same bi- or multimodal area density distribution in all levels, but with changing amplitudes of the different modes. A unimodal distribution, in which the position of the mode changes with depth level, on the other hand, would indicate a concerted reaction of the entire population irrespective of the number of cryptic species involved. Consequently, Hartigan's Dip Test (Hartigan and Hartigan, 1985) was performed, to test for unimodality in the data.

\subsection{Data analysis}

All statistical tests were conducted in R v. 2.13.0 (R Development Core Team, 2011). Stable isotopic data (i.e. $\delta^{18} \mathrm{O}$ ) of shells of $G$. ruber can be considered to be representative for the environmental change, especially the amount of freshwater inflow at the time of deposition of Sapropel S5. For that reason, a general correlation between stable isotopes and MAD should be tested using independent linear regressions. Several assumptions to use a model I linear regression were violated, so a Kendall-Theil robust line fitting (KTRLF) (Kendall, 1938; Theil, 1950; Sen, 1968) was implemented in R v. 2.13.0 (R Development Core Team, 2011) using equations given in Helsel and Hirsch (2002), and the equation of Conover (1980) to calculate the intercept. Besides being robust against all disturbances as long as values are measured on a meaningful scale, this method also offers the benefit that the confidence intervals of the MAD do not need to be prescribed.

\subsection{Comparison with reference values from present-day samples}

To obtain values for comparison of our results with a representative reference value, we analysed core-top samples $(1-0 \mathrm{~cm})$ from multicorer cores, using the same procedures as outlined above. For Globigerinoides ruber (pink), Orbulina universa, and Globorotalia inflata we used a sample from Cruise POS334, Leg 79 from the Western Mediterranean Sea north of Africa (Schulz et al., 2006). This sample has been chosen because it derives from a region where the abundance of these three species is the highest in the 


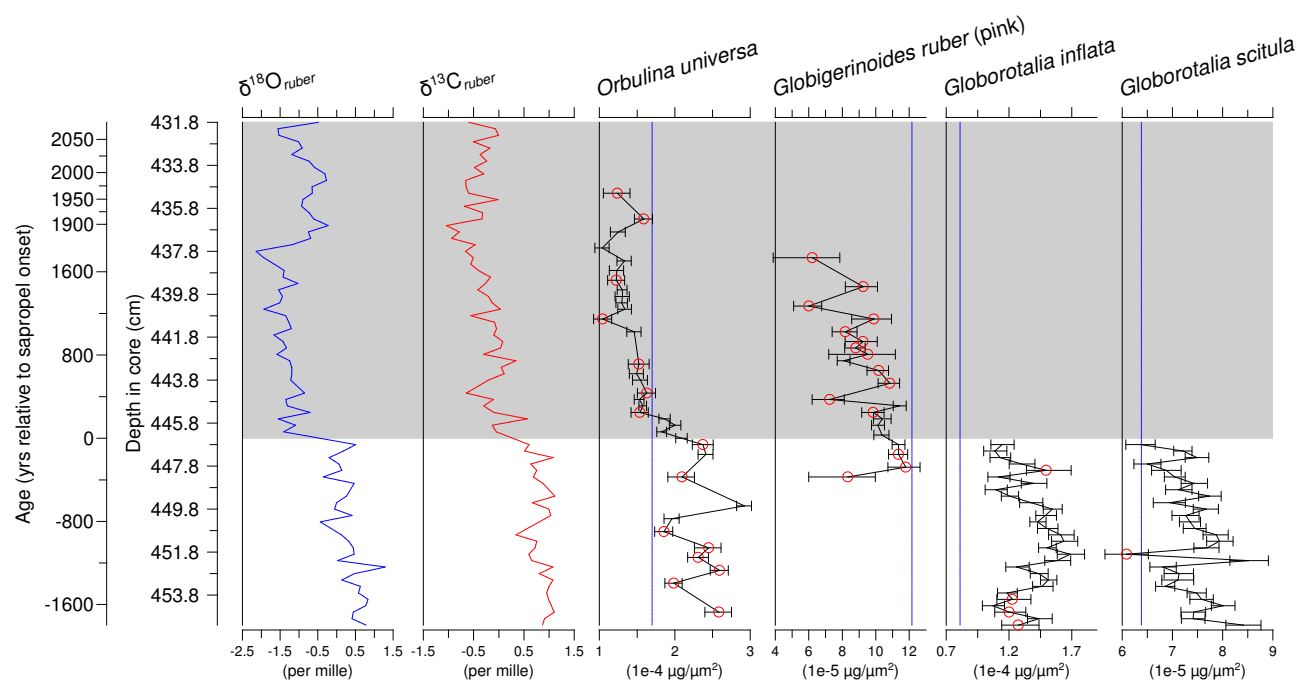

Fig. 3. Records of mean area density (MAD) for the four selected species of planktonic Foraminifera across the onset of Sapropel S5 in core M51-3/SL104, with $95 \%$ confidence intervals. Red circles highlight samples where the MAD value is based on fewer specimens $(<6$ for Orbulina universa and $<10$ for all other species). The blue vertical line shows the MAD value of a modern reference for each species. The grey shaded area represents the extent of the sapropel (Fig. 2). Ages are given in years relative to sapropel onset.

Mediterranean Sea at present (Hayes et al., 2005). Globorotalia scitula is not abundant enough anywhere in the Mediterranean today. Modern references for that species were therefore taken from Cruise M34-3, Station 3810-2 (Bleil et al., 1997) from the Southern Atlantic Ocean, halfway between Africa and South America, where the distribution of the species in modern core tops indicates a proximity to its ecological optimum (Kučera et al., 2005). Considering typical sedimentation rates in the vicinity of the two modern samples $\left(3.6 \mathrm{~cm} \mathrm{kyr}^{-1}\right.$ in the Atlantic (Seiter et al., 2005) and $7.2 \mathrm{~cm} \mathrm{kyr}^{-1}$ in the Western Mediterranean (Hayward et al., 2009)) and the date when the samples were collected (2006 for POS334 and 1996 for M34-3/3810-2), only a small proportion of the Foraminifera in these samples is likely to have been deposited during the industrial period with $p \mathrm{CO}_{2}$ values more than 20 per cent above the pre-industrial baseline. Therefore, we consider the analysed Foraminifera to be largely representative of pre-industrial $p \mathrm{CO}_{2}$ levels.

Using those recent values as basis for normalization (Eq. 2), MAD values of the different species could be made comparable with each other. Subsequently, Yates $\chi^{2}$ Test of Association (Yates, 1934) could be used to test the independence of the MAD from environmental factors, and the strength of a potential association could be determined by calculating the $\phi$ Coefficient of Association (Cramér, 1946). For this step only, post-extinction MAD values of Globorotalia scitula from two samples from within the sapropel ( 443.05 and $442 \mathrm{~cm}$ ) were used to confirm the general trends.

$\mathrm{MAD}_{\text {norm }}=\frac{\text { MAD }-\mathrm{MAD}_{\text {recent }}}{s(\mathrm{MAD})}$, where $\mathrm{MAD}_{\text {norm }}$ is the normalized MAD per sample, on the basis of the recent comparison value $\mathrm{MAD}_{\text {recent }}$ and standard deviation $s(\mathrm{MAD})$ of all measured MAD values of the species.

\section{Results}

The relative and absolute abundances of the studied species, together with the position of the regionally established local extinctions and re-populations are shown in Fig. 2. The stable isotope records of G. ruber (white), shown in Fig. 3, confirmed a close association of the onset of the sapropel with freshwater discharge and the local extinctions of $G$. inflata and G. scitula.

The MAD data for all species are depicted in Fig. 3. Globigerinoides ruber (pink) yielded relatively few specimens that were suitable for weighing, so that only 0 20 specimens/sample fulfilled the criteria for weighing (Table S1), with a median sample size of just $\tilde{n}=4$. The data were normally distributed with $p=0.275$ according to a Shapiro-Wilk test (Shapiro and Wilk, 1965), with a mean MAD of $9.45 \times 10^{-5} \mu \mathrm{g} \mu \mathrm{m}^{-2}$. Shells of $G$. ruber (pink) were always lighter than in the modern reference, where an MAD of $12.16 \times 10^{-5} \mu \mathrm{g} \mu \mathrm{m}^{-2}$ was determined (Fig. 3). In $O$. universa $2-22$ specimens/sample $(\tilde{n}=6)$ fell in the respective size range for weighing (Table $S 1$ ), yielding MAD data that were not normally distributed $(p=0.034)$. The mean MAD of that species is $1.74 \times 10^{-4} \mu \mathrm{g} \mu \mathrm{m}^{-2}$, which is close to the value derived from the modern references $\left(1.70 \times 10^{-4} \mu \mathrm{g} \mu \mathrm{m}^{-2}\right)$.

To test for the potential influence of non-constant mixing of different cryptic species of $O$. univers $a$ on the mean values 


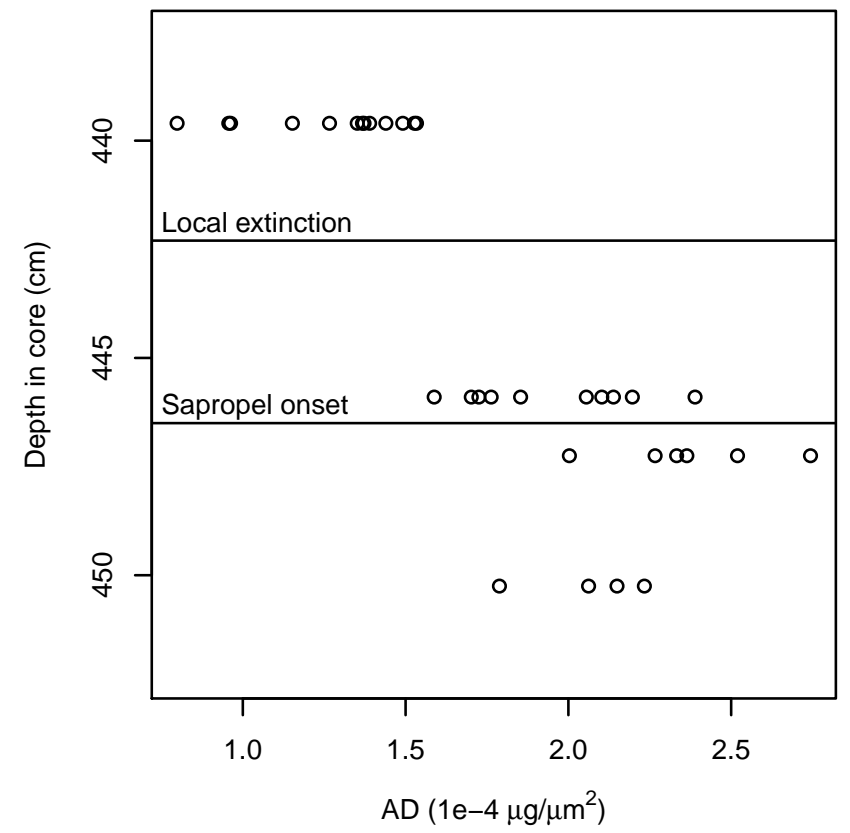

Fig. 4. Distribution of area density (AD) values of individual Orbulina universa specimens in individual samples across Sapropel S5 in core M51-3/SL104. These samples represent conditions before and after the onset of Sapropel S5 as well as conditions after the first local extinction of the species (Fig. 2). Hartigan's Dip Test (Hartigan and Hartigan, 1985) indicates no significant deviation from unimodality in any of the samples, suggesting that the detected trend of decreasing mean area density over time within the sapropel is not the result of a changing community composition, but a general trend in the overall calcification of the shells of the species.

in the samples, weight measurements of individual specimens for four selected depth levels were performed: samples $17+18$ and $27+28$ before sapropel onset, sample 32 after sapropel onset, and sample 53 after the first local extinction in sample 44. The data (Fig. 4) for all samples showed a general trend towards lighter shells in the upper samples, with a generally similar variability of the weight. No significant deviation from unimodality could be detected in any of the depth levels $\left(p_{\min }=0.240\right)$.

Globorotalia scitula yielded between 8 and 50 specimens/sample $(\tilde{n}=25)$ for weighing purposes (Table $\mathrm{S} 1)$. The MAD was normally distributed $(p=0.950)$, but with a mean MAD of $7.34 \times 10^{-5} \mu \mathrm{g} \mu \mathrm{m}^{-2}$ G. scitula was the least intensely calcified of the studied species. The MAD of this species in M51-3/SL104 was nearly always higher than in the recent material from the Southern Atlantic $\left(6.38 \times 10^{-5} \mu \mathrm{g} \mu \mathrm{m}^{-2}\right)$.

Between 4 and 31 specimens/sample $(\tilde{n}=15)$ of $G$. inflata were suitable for weighing (Table S1), providing normally distributed MAD data $(p=0.109)$ with a mean of $1.36 \times 10^{-4} \mu \mathrm{g} \mu \mathrm{m}^{-2}$. As in G. scitula, shells of $G$. inflata were always heavier in the studied samples than in modern Mediterranean sediments $\left(0.81 \times 10^{-4} \mu \mathrm{g} \mu \mathrm{m}^{-2}\right)$. It is worth

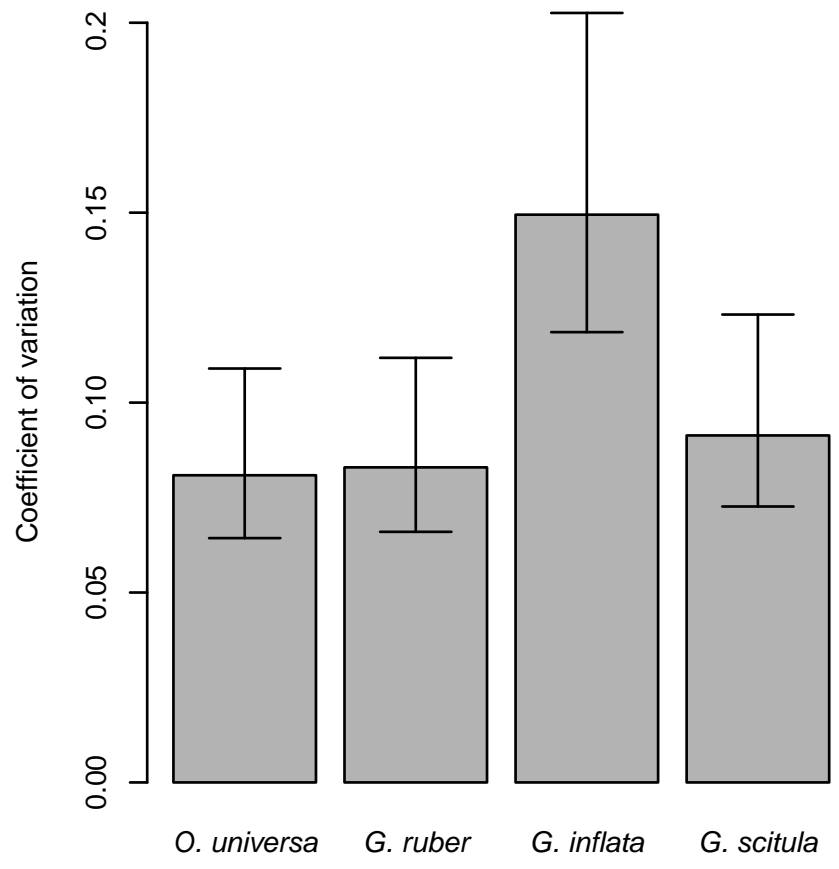

Fig. 5. Variance of the mean area density values for the four studied species, expressed as coefficient of variation. The variance is based on replicated measurements of random subsamples from samples $35,32,6$, and 21 in core M51-3/SL104. The $95 \%$ confidence intervals were estimated after Vangel (1996, Eq. 16).

mentioning, that the variance of the MAD of $G$. inflata, as obtained from the coefficients of variation, was significantly larger than in any of the other species investigated (Fig. 5).

In order to investigate to what degree the obtained MAD mean values are representative of the samples, we took advantage of the data obtained in the procedure to estimate the confidence interval. These data allowed us to estimate the minimum number of specimens to be weighed together to obtain a representative MAD for each species. These data revealed that in all species a change in the slope of the regression between the size of the confidence interval and the number of specimens $n$ considered can be observed. In samples larger than that threshold size, the confidence interval decreased slowly with further increasing sample size in comparison to samples smaller than that threshold size. To determine such threshold values for each species objectively, two regression lines were fitted to the data, one to the steep slope for small sample sizes, one to the shallow slope for larger sample sizes. The border between those two subsets per species was chosen such that the product of the $R^{2}$ values of both regression lines was minimal (Fig. 6). The resulting threshold sample sizes were $n=5$ for $O$. universa, $n=4$ for $G$. ruber (pink), $n=22$ for G. scitula, and $n=11$ for $G$. inflata. Thus, with the exception of $G$. scitula, the target samples sizes used in this study to determine MAD should yield a good approximation of the MAD value. In G. scitula, 

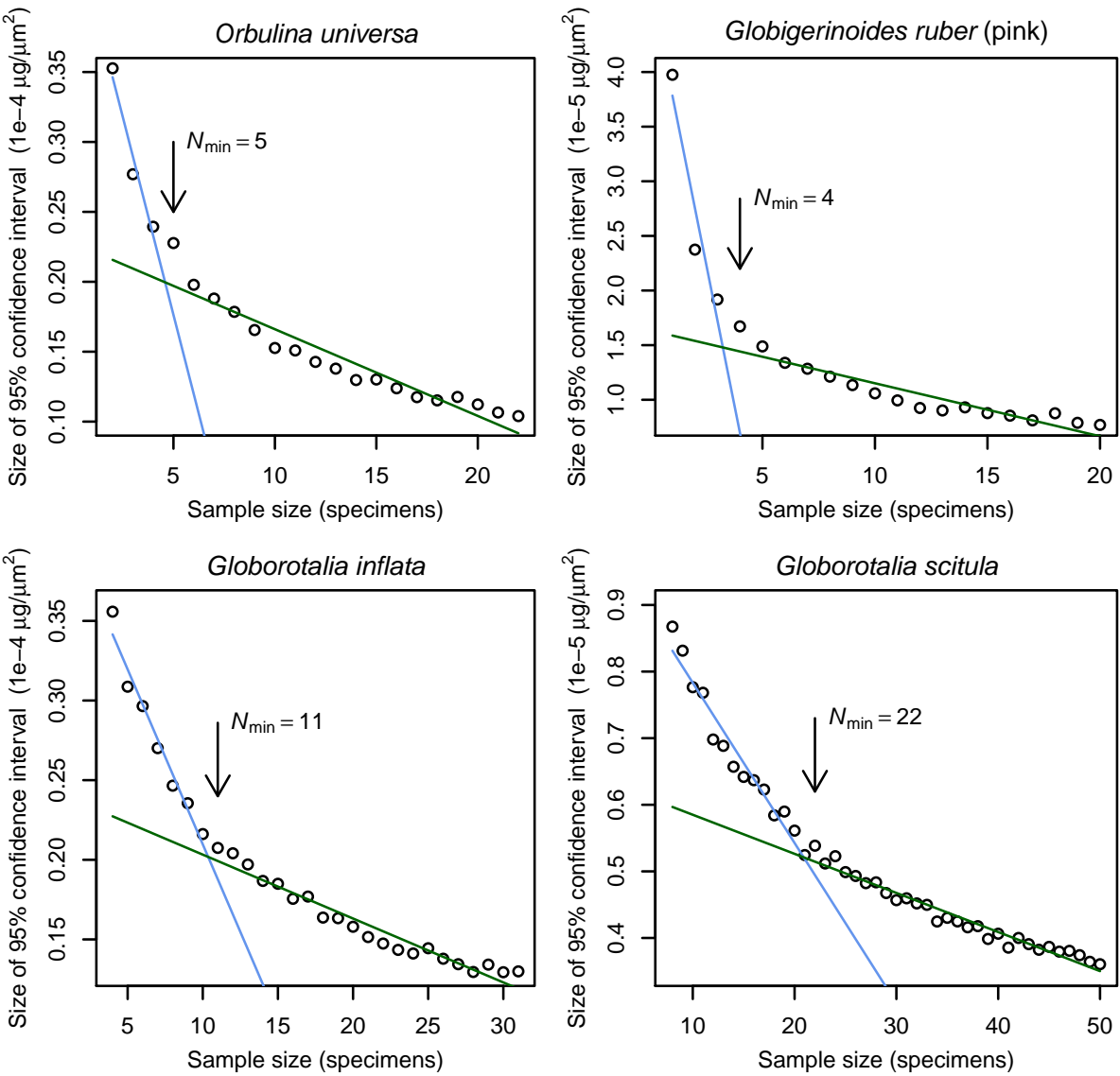

Fig. 6. Two-step regression for the estimation of a suitable minimal sample size for mean area density determination in each of the four studied species during the onset of Sapropel S5 in core M51-3/SL104. The two regression lines where chosen such that the product of their respective $R^{2}$ values is minimal.

a larger sample size would have been desirable to reduce the uncertainty of the MAD values.

\section{Discussion}

\subsection{Environmental change at the onset of Sapropel S5}

The stable isotope curves of G. ruber showed a large change with the onset of Sapropel S5. The values and magnitude of change are compatible with hypotheses attributing this phenomenon to the inflow of freshwater from Africa with much lower isotopic values in comparison with seawater (Gasse, 2000; Hoelzmann et al., 2000), due to an enhanced monsoon activity over Africa (Rossignol-Strick, 1983; Rohling et al., 2002; Moller et al., 2012). In response to the freshwater influx, a layer with strongly reduced salinity is assumed to have formed at the top of the water column in the Eastern Mediterranean, causing a stagnation of the vertical circulation and the deposition of Sapropel S5 (Rossignol-Strick et al., 1982; Myers et al., 1998; Rohling et al., 2000, 2009). The collapse of the vertical circulation of the water column occurred very rapidly, within $40 \pm 20 \mathrm{yr}$ (Marino et al., 2007) after the onset of the elevated freshwater influx. The $\delta^{18} \mathrm{O}$ stable isotopic signal is found almost coevally in shallow-dwelling and deep-dwelling species of planktonic Foraminifera, including the here-studied G. scitula and G. inflata (Rohling et al., 2004), indicating that the resulting perturbation of the upper water column affected a major portion of the habitat of planktonic Foraminifera.

While anoxic conditions developed in the deeper water column (e.g. Rinna et al., 2002) the surface waters were subject to different environmental changes. The data indicate that the sea surface temperature rose by about $3^{\circ} \mathrm{C}$ during the first $1000 \mathrm{yr}$ after the onset of the sapropel, and remained high for the remainder of sapropel deposition (Marino et al., 2007). Concomitant with the freshwater influx must have been a reduction of surface water salinities towards normal marine values (compare, for instance, Wüst, 1961; Rohling et al., 2009). Because a palaeo-salinity reconstruction on the basis of $\delta^{18} \mathrm{O}$ is complicated in the Eastern Mediterranean Sea (Rohling et al., 2004), an alternative approach used the isotopic composition of alkenones (van der Meer et al., 2007). This approach indicates a rapid drop in surface 

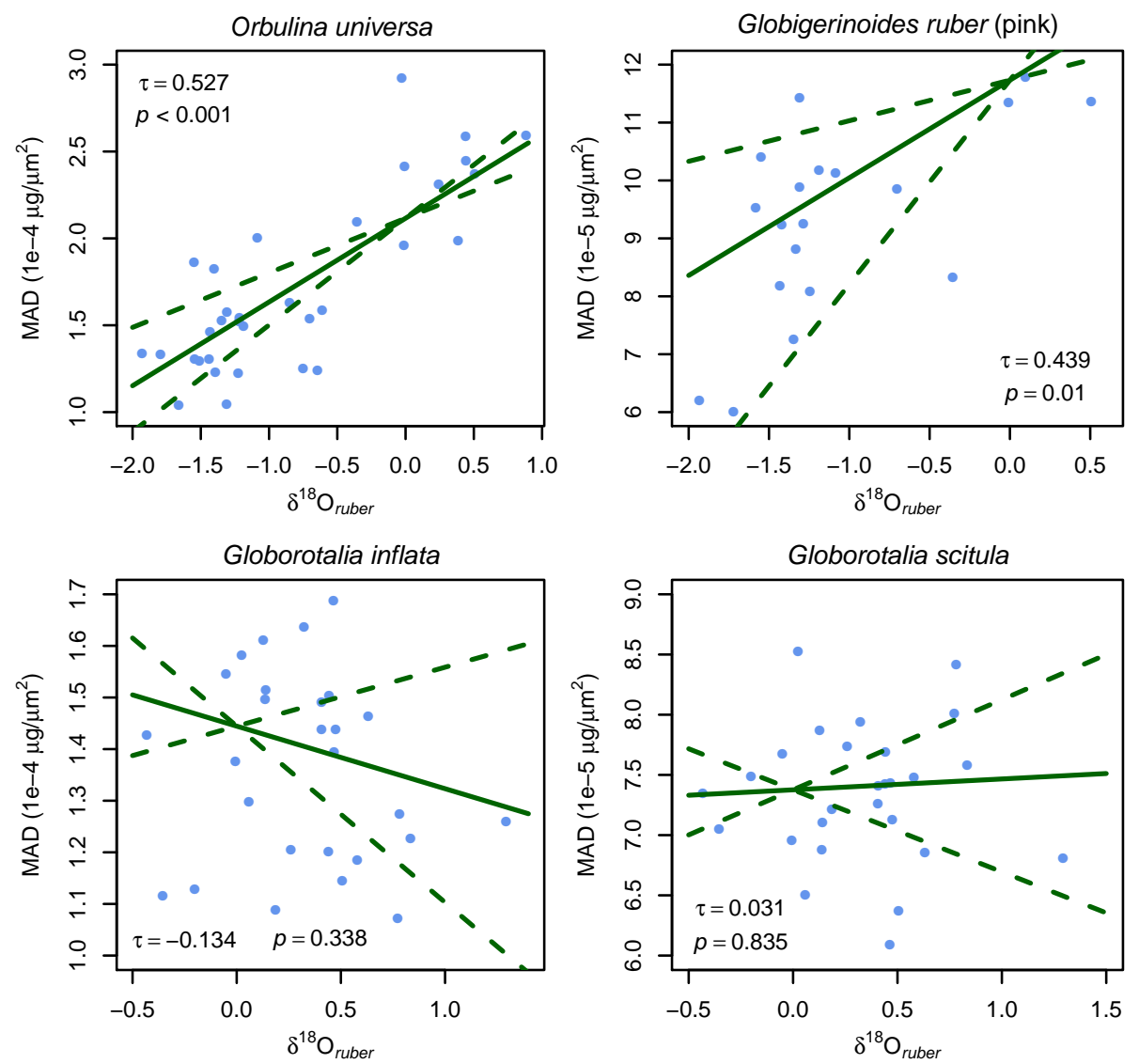

Fig. 7. Kendall-Theil robust line fitting (solid lines) of the mean area density (MAD) in the investigated four species with $\delta^{18} \mathrm{O}$ data of Globigerinoides ruber during the onset of Sapropel S5 in core M51-3/SL104. The MAD data are significantly positively correlated with isotopic data for the two shallow-dwelling species. Dashed lines represent the $95 \%$ confidence interval of the regression lines.

water salinity from c. 39 to c. 35 psu with the onset of the sapropel, which then prevailed for about $2000 \mathrm{yr}$, i.e. for the whole time interval investigated here. Such change in the surface salinity is unlikely to have affected the physiology of the Foraminifera by itself, but it would have led to a large change in carbonate chemistry of the surface water, resulting in decreased calcite saturation (empirical results, e.g. by Trask, 1937; Chierici and Fransson, 2009.)

\subsection{Abiotic factors vs. physiological stress}

In order to test whether abiotic factors have influenced the calcification intensity of the studied Foraminifera, the MAD values were compared to the $\delta^{18} \mathrm{O}$ record of Globigerinoides ruber, which here serves as a proxy of surface water composition. A KTRLF indicates the presence of a significant relationship between $\delta^{18} \mathrm{O}$ and MAD in G. ruber (pink) and $O$. universa (Fig. 7). Additionally, in O. universa a significant drop in the MAD from $2.30 \times 10^{-4} \mu \mathrm{g} \mu \mathrm{m}^{-2}$ to $1.44 \times 10^{-4} \mu \mathrm{g} \mu \mathrm{m}^{-2}$ ( $\tilde{W}=257, \bar{p}<0.001$ according to a Mann-Whitney $U$ Test) can be observed, which coincides with the fast decrease of stable isotope values in shells of
G. ruber at the onset of the sapropel. In contrast to those findings, there is no correlation between MAD and stable isotopes detectable in G. scitula and G. inflata. These species calcify in a deeper layer in the ocean and both exhibit a local extinction at the onset of the sapropel, so the lack of correlation between their calcification intensity and $\delta^{18} \mathrm{O}$ only refers to the unperturbed conditions prior to the freshwater-induced stratification of the water column.

Although the latter two species cannot provide information on their reaction to environmental change at the onset of the sapropel deposition, their MAD values may provide clues to the general relationship between calcification intensity and surface water chemistry. Because the global sea level was lower than at present during the transitional and deglacial times prior to sapropel deposition, the connection of the Mediterranean Sea with the Atlantic Ocean was more restricted, and the resulting increase in residence time of seawater made the Mediterranean saltier (Rohling, 1999). A comparison of the MAD values of the two deeperdwelling species indicates that at that time, they built consistently stronger calcified shells than the reference Holocene populations (Fig. 3). A similar pattern is observed for the 
Table 1. Results of Spearman's Rank-Order Correlation of the mean area density of the species with its abundance. The analysis was performed for the relative abundance (in per cent) and the calculated accumulation rate (in specimens $\mathrm{m}^{-2} \mathrm{yr}^{-1}$ ).

\begin{tabular}{lccrc}
\hline & \multicolumn{2}{c}{ Relative abundance } & \multicolumn{2}{c}{ Accumulation rate } \\
Species & $\bar{\rho}$ & $\bar{p}$ value & $\bar{\rho}$ & $\bar{p}$ value \\
\hline O. universa & 0.149 & 0.397 & 0.085 & 0.631 \\
G. ruber (pink) & 0.264 & 0.265 & 0.115 & 0.622 \\
G. scitula & 0.024 & 0.804 & -0.075 & 0.692 \\
G. inflata & 0.263 & 0.190 & 0.082 & 0.663 \\
\hline
\end{tabular}

populations of the two surface-dwelling species in sediments prior to the onset of the sapropel, where $O$. universa also calcifies more than the modern reference, but the pattern is reversed in the sapropel, where both surface-dwelling species seem to have calcified lighter than the reference (Fig. 3). As a result, there is a strong and highly significant relationship between MAD values of all species normalized against their modern references (Eq. 2), and $\delta^{18} \mathrm{O}$ values of $G$. ru$\operatorname{ber}\left(\chi^{2}=70.1393, \mathrm{~d} f=1, p<0.001, \phi=-0.825\right.$; Fig. 8). Because of the re-appearance of one of the deep-dwelling species, Globorotalia scitula, within the investigated portion of the sapropel (Fig. 2), the implied abiotic forcing of calcification in the studied Foraminifera can be further tested. To this end, two additional samples of this species from within the sapropel have been analysed for MAD. In both cases, the calcification was lighter than the modern reference (Fig. 8), supporting the abiotic forcing hypothesis.

In order to test the alternative hypothesis of calcification intensity being linked to varying levels of physiological stress, the MAD values were compared to changes in the abundances of the species (relative abundance and accumulation rate) as a measure of the suitability of the environment for the species. Close to the environmental optimum of a species its production rates should be highest and according to de Villiers (2004) we should expect to find highest calcification rates under such favourable environmental conditions. However, in no species a significant correlation between the relative abundance or the accumulation rate and the MAD could be detected (Figs. 9 and 10, and Table 1). To assess the existence of such relationship, when all species are considered, in analogy with the concept in Fig. 8, the normalized (Eq. 2) MAD data of all species were plotted against their standardized accumulation rates. In contrast to the high correlation between stable isotopic data and normalized MAD, no correlation between standardized abundances and normalized MAD values could be detected $\left(\chi^{2}=0.9563, \mathrm{~d} f=1\right.$, $p=0.328, \phi=-0.110$, Fig. 11).

These results indicate that changes in calcification intensity occurred irrespective of changes in productivity of the studied species. Since the magnitude of the considered values of productivity reached all the way to total demise of

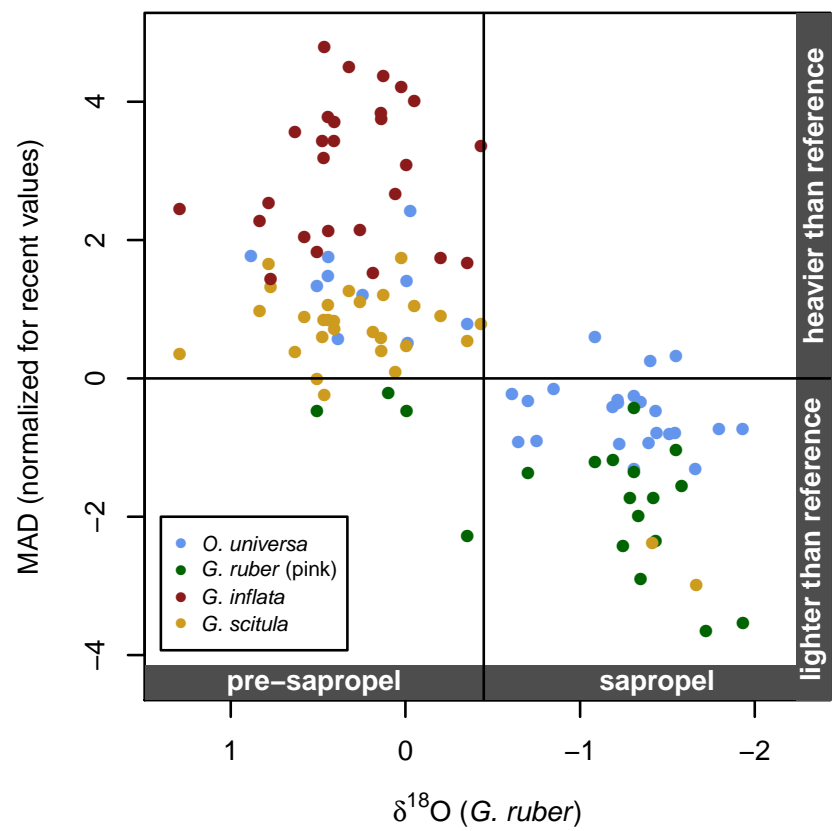

Fig. 8. Correlation between normalized (for recent samples) mean area density (MAD) data of the four investigated species and $\delta^{18} \mathrm{O}$ values of Globigerinoides ruber during the onset of Sapropel S5 in core M51-3/SL104. All species reflect a consistent pattern of stronger calcification during times of higher isotopic values.

the species, the results indicate that calcification in planktonic Foraminifera is de-coupled from environmental stress and likely not affected by trade-offs between biomineralization and biomass production. This decoupling is observed at a timescale of centuries, leaving a possibility that the reaction of calcification on physiological stress could be a short-term, threshold process, operating first at near-lethal levels of stress such as would be expected immediately prior to extinction. To this end, we have examined the MAD values in the last samples prior to local extinctions (Fig. 2) in all four species. None of the MAD values of the last sample prior to extinction were the lowest values for the respective species in the studied interval (Fig. 3). This observation indicates either an absence of a notable effect of stress on calcification or the existence of such a relationship only at timescales of a few decades or less, that could not be resolved by our sampling.

\subsection{Factors influencing calcification intensity in plank- tonic Foraminifera}

The observed trends in calcification intensity of the studied species are very unlikely to be the result of changing carbonate preservation throughout the time interval. Due to the high salinities in the Eastern Mediterranean, the seawater saturation with respect to calcite has likely remained high (Schneider et al., 2007), so that no calcite dissolution should be expected. In fact, from our observation the preservation of Foraminifera within the sapropel was better than 

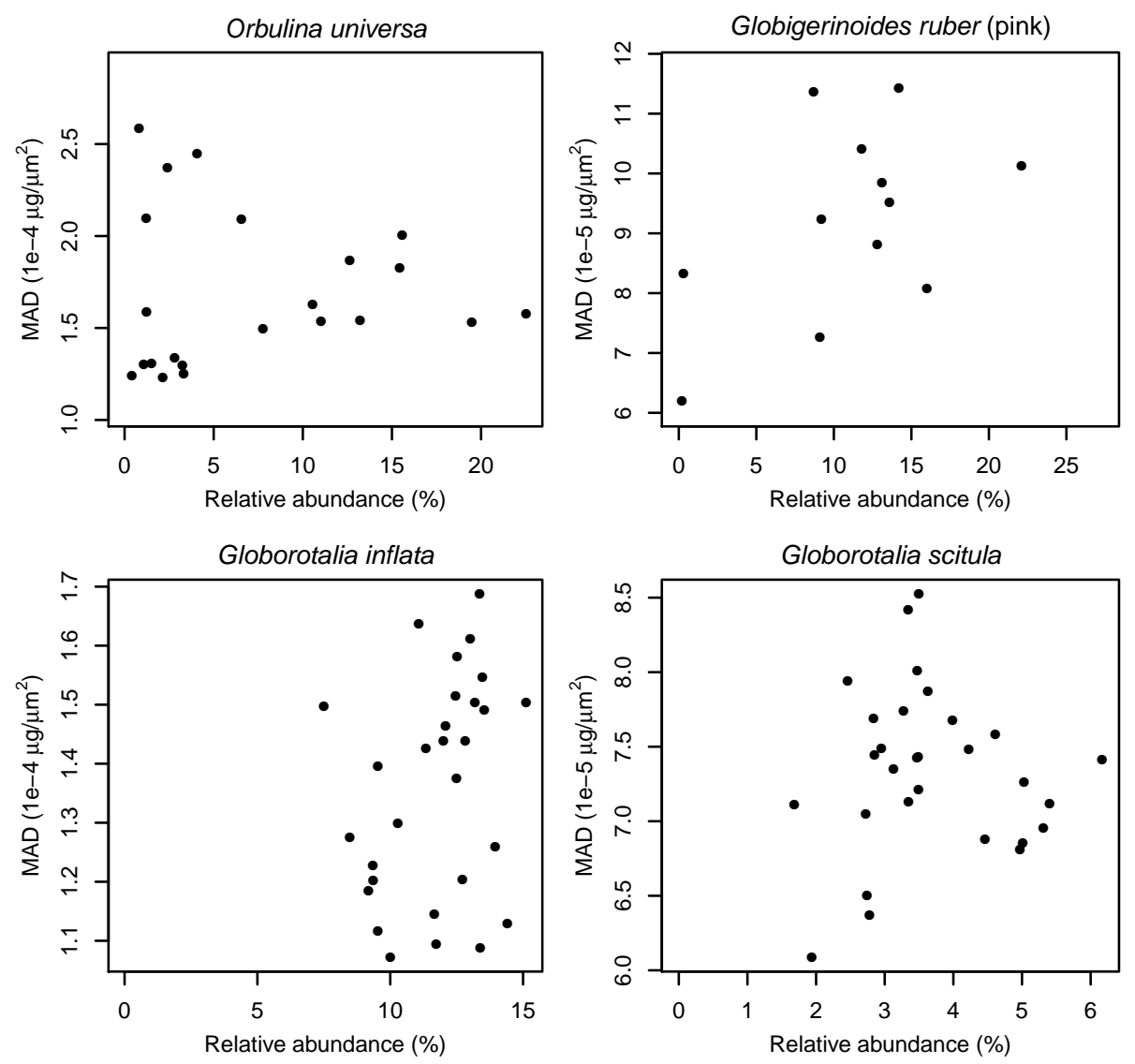

Fig. 9. Correlation between relative abundance and mean area density (MAD) of the four investigated species. No significant correlation can be observed, indicating that the calcification rate and competitiveness of the species were independent of each other during the onset of Sapropel S5 in core M51-3/SL104.

before the sapropel, with pristine, glassy specimens of even tiny thin-walled species. This effect is directly comparable to the "sealing" effect in hemipelagic sediments as described by Pearson et al. (2001). The final evidence against carbonate dissolution as a factor affecting the measured MAD is the continuous presence throughout the studied interval of pteropods - which are very sensitive to carbonate dissolution due to their aragonitic mineralogy.

In addition to dissolution, the precipitation of inorganic secondary calcite in pre-sapropel samples could also influence our results. The precipitation of secondary calcite in the pre-sapropel sediment, however, is unlikely because all specimens appear clean and well preserved even before the sapropel, and the MAD values of G. ruber (pink) in pre-sapropel sediments are similar to the modern reference. If secondary inorganic precipitation affected the MAD values, it should have done so equally strongly for all species, because such a process is inorganic and could not be species-selective.

Of the studied species, Orbulina universa is known to harbour three distinct cryptic genetic types. If these genetic types, which likely represent biological species (de Vargas et al., 1999), calcify differently, the observed trend in the species could reflect a change in their relative proportions. This possibility has been investigated by individually weighing specimens from four selected time horizons (Table S2, Fig. 4). These data indicate a shift of the entire population towards lower calcification intensities, with kernel density curves for each of the four levels not significantly different from unimodality. While this is no proof for a constant community composition, it shows that our calculated MAD values represent a reaction of the whole community, not a switch from one bimodal state to another. The pre- and post-sapropel-onset MAD distributions are so distinct that if they were solely due to differences in the calcification among different cryptic genetic types, then these values alone could be easily used to distinguish among them, which is difficult to reconcile with their cryptic nature.

Excluding the effect of carbonate dissolution and genotype abundance fluctuations on the observed decrease in MAD with the onset of the sapropel, calls for an explanation involving the effect of shifts in the parameters of the ambient water column. Orbulina universa shows the strongest reaction to the changing environment, with a clear drop in MAD at the onset of the sapropel, a continuous decrease of calcification 

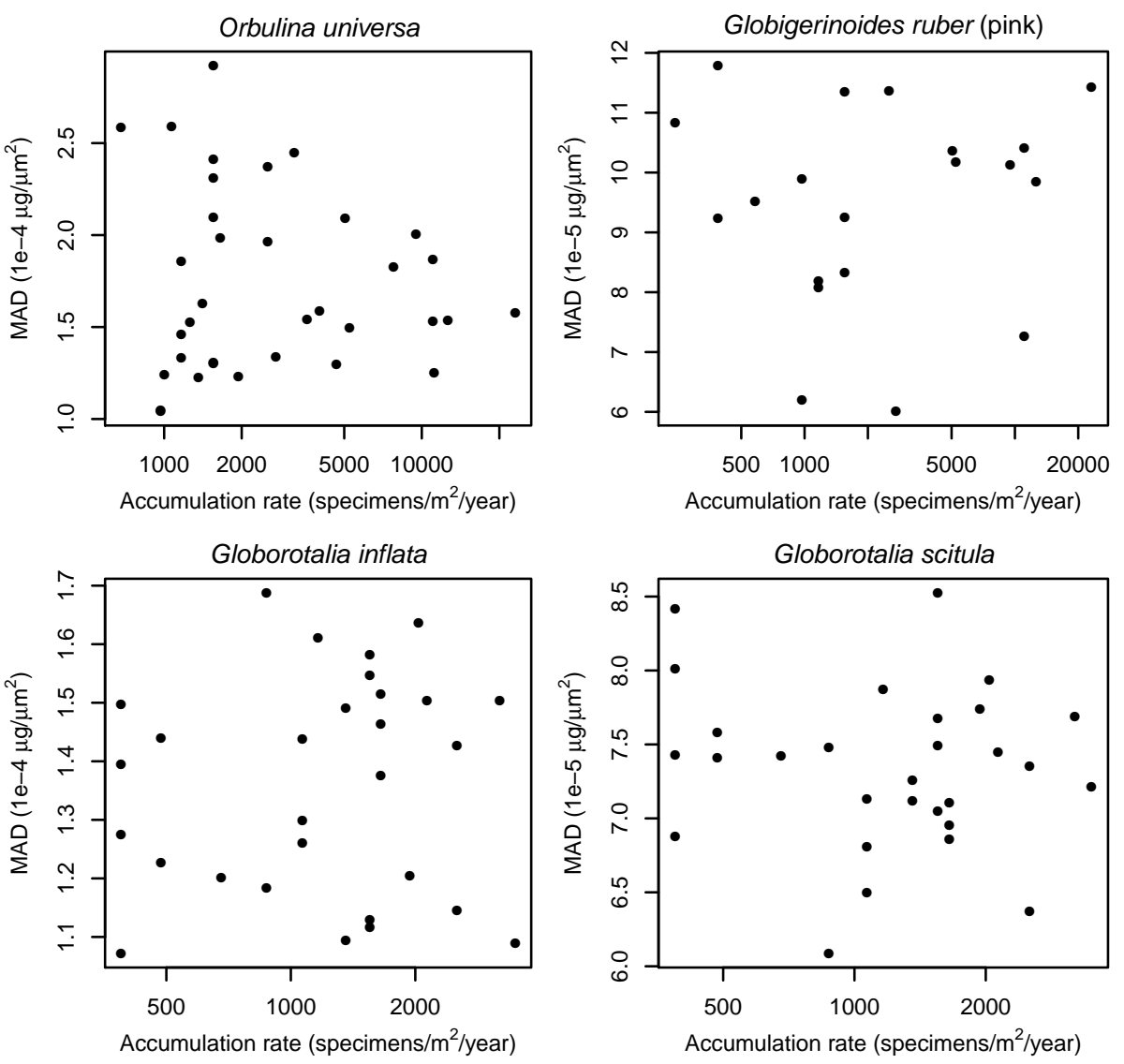

Fig. 10. Correlation between accumulation rates and mean area density (MAD) of the four investigated species. No significant correlation can be observed, indicating that the calcification intensity and productivity of the species were not influenced by each other during the onset of Sapropel S5 in core M51-3/SL104. Note the log-scaling of the $x$ axis.

intensity within the sapropel, and a strong relationship with stable isotopic data and thus probably freshwater influx. Globigerinoides ruber (pink) shows similar results, though the drop in MAD with sapropel onset could not be clearly tested because the species was not abundant enough at that time. Both species calcify in the upper water column (Pujol and Vergnaud Grazzini, 1995; Rohling et al., 2004) and were therefore strongly influenced by the freshwater inflow, thriving in a water mass with presumably reduced salinity in comparison to normal Eastern Mediterranean conditions (van der Meer et al., 2007). Because multiple parameters changed in parallel during the onset of the sapropel, it is difficult to isolate the primary abiotic factor that may have led to reduced calcification intensity in these species.

Obviously, the freshwater influx have not caused reduced carbonate production, since Moller et al. (2012) reported a short-lasting rise in Ca content in the sediment from 13.9 to 29.9 per cent with the onset of the sapropel, followed by a return to pre-sapropel conditions, decoupled from changes in MAD of the shallow-dwelling species.

Therefore, we entertain the possibility that the observed reduction in calcification intensity could be due to changes in seawater carbonate chemistry. Such a link seems to be the most commonly invoked hypothesis explaining differences in calcification rates among planktonic Foraminifera (Barker and Elderfield, 2002). Because it may be assumed that $\delta^{18} \mathrm{O}$ of $G$. ruber was correlated with surface salinity during the onset of Sapropel S5 (Gasse, 2000; Hoelzmann et al., 2000), the close link between this variable and the MAD of the studied species is consistent with a dominant forcing by carbonate chemistry of the ambient seawater, in line with the observations by Bijma et al. (1999), Barker and Elderfield (2002), and Marshall et al. (2013). Higher carbonate saturation states at the time before sapropel deposition, as suggested by higher MAD values (Fig. 3), were most likely the result of higher salinity in the glacial water body in the Eastern Mediterranean Sea, which developed because of longer residence times due to the lower sea level restricting water exchange with the open ocean (Rohling, 1999).

The lack of a relationship between MAD in $G$. inflata and G. scitula, and $\delta^{18} \mathrm{O}$ of $G$. ruber in the interval prior to sapropel deposition likely reflects the deeper calcification depth of those species, compared to $O$. universa. We hypothesize that the subsurface layer, where the calcification 


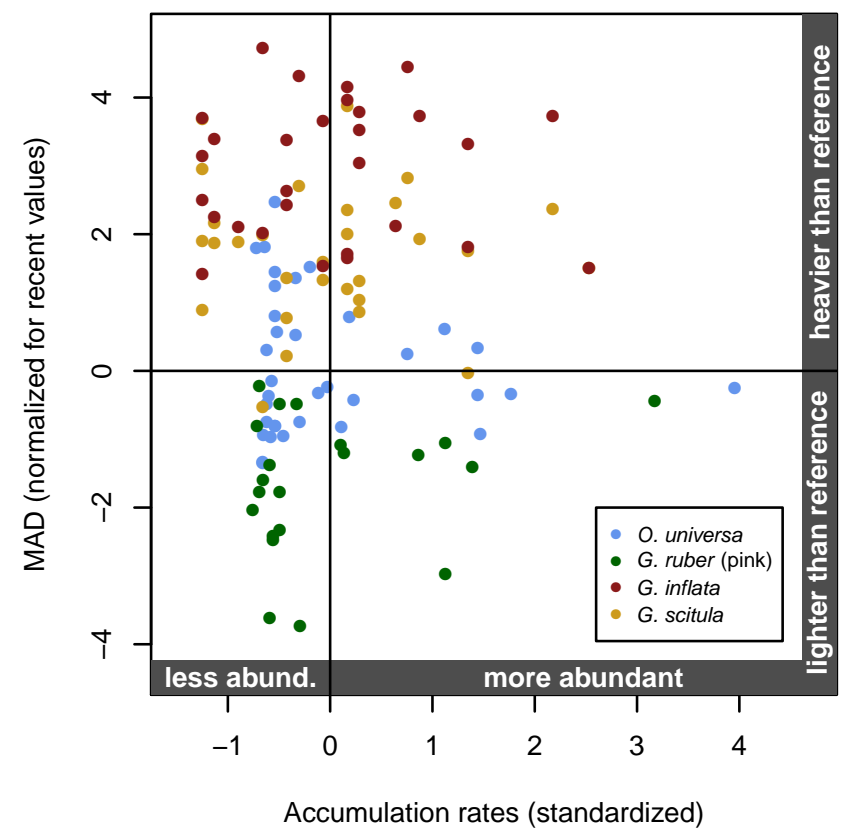

Fig. 11. The relationship between normalized (for recent samples) mean area density (MAD) data of the four investigated species and their standardized accumulation rates during the onset of Sapropel S5 in core M51-3/SL104. The lack of correlation indicates that calcification intensity is not related to stress on the studied timescale.

of these species is likely to have been concentrated (Rohling et al., 2004), experienced a weaker reaction to environmental changes prior to sapropel deposition than the surface layer. This possibility is also suggested by results from Rohling et al. (2004, Fig. 5). This study from the same time interval and region shows, that the general trend of reduced stable isotopic values can be found in shell calcite of a variety of planktonic Foraminifera, including G. scitula. However, the deeper dwelling species show isotopic values indicating that their habitat was less affected by the freshwater discharge. In accordance with our results (compare Fig. 8) this suggests, that the environmental change leading to the deposition of Sapropel S5 affected the deeper water column as well, but to a lesser degree. A broader calcification depth in G. inflata, not limited to the surface layer, is supported by the larger variability in calcification intensity in that species (Fig. 5).

In summary, the analysis using normalized calcification intensity data of all species together strongly supports a dominant abiotic forcing of calcification intensity in planktonic Foraminifera at timescales of decades to centuries. While all species support a relationship between proxies of surface water properties and MAD, no correlation between MAD and abundance of the studied species could be observed. This relation indicates a strong influence of the environmental change itself on calcification in all species, but no influence of the stress associated with that change, that would be reflected in the changing productivity of a species as inferred from its accumulation rates. This is further supported by the complete lack of a reaction of calcification intensity on terminal environmental stress leading to local extinction in any of the species investigated in this study. These results support the use of calcification intensity in planktonic Foraminifera as an environmental proxy. Even if we could not isolate, which environmental factors acted on the calcification process in which combination, it is likely that the process of calcification is not complicated by insurmountably complex biological relationships, and the observations in this study are consistent with the hypothesis that calcification in planktonic Foraminifera is driven by carbonate chemistry of the ambient water.

\section{Conclusions}

Our study has shown that the calcification intensity in four species of planktonic Foraminifera was likely related to environmental changes during the onset of Sapropel S5 in the Eastern Mediterranean. Specifically, we observe significant relationships between MAD and a proxy of surface water properties, and no relationship between calcification and productivity of the studied species.

Concerning our hypotheses we can thus state, that we were only able to observe long-term changes associated with abiotic factors of the environmental change (hypothesis a1). Neither long-term reactions of the calcification intensity and optimal growth conditions (hypothesis a2) nor short-term reactions of the calcification intensity during times of terminal environmental stress (hypothesis b) could be observed in our data set. This observation supports the use of the calcification intensity of planktonic Foraminifera as a palaeoproxy for environmental reconstructions. Even though the exact combination of environmental factors acting on calcification of planktonic Foraminifera during the natural experiment of the onset of Sapropel S5 could not be disentangled, the observed patterns are consistent with calcification intensity being driven by carbonate chemistry of the ambient seawater.

\section{Supplementary material related to this article is available online at http://www.biogeosciences.net/10/ 6639/2013/bg-10-6639-2013-supplement.zip.}

Acknowledgements. The authors want to thank the responsible editor Tina Treude and two anonymous referees for their constructive comments on the discussions version of this article. The authors acknowledge the financial aid of the Land Baden-Württemberg (granted in the form of the Landes-Graduierten-Förderungs-Gesetz - LGFG), which provided the financial basis for the principal author. Tobias Moller received funding through the German Research Foundation DFG-grant SCHU1605/3-1. We are thankful 
to Hartmut Schulz and Barbara Donner for providing the material of the modern references, and Agnes Weiner for help with the final editing of the manuscript. The others members of the Minigraduiertenprojekt in Tübingen are acknowledged for their invaluable help and support in many situations, which cannot be listed in detail.

Edited by: T. Treude

\section{References}

Aldridge, D., Beer, C. J., and Purdie, D. A.: Calcfication in the planktonic Foraminifera Globigerina bulloides linked to phosphate concentrations in surface waters of the North Atlantic Ocean, Biogeosciences, 9, 1725-1739, doi:10.5194/bg-9-17252012, 2012.

Aurahs, R., Treis, Y., Darling, K., and Kučera, M.: A revised taxonomic and phylogenetic concept for the planktonic foraminifer species Globigerinoides ruber based on molecular and morphometric evidence, Mar. Micropaleontol., 79, 1-14, doi:10.1016/j.marmicro.2010.12.001, 2011.

Barker, S. and Elderfield, H.: Foraminiferal calcification response to glacial-interglacial changes in atmospheric $\mathrm{CO}_{2}$, Science, 297, 833-836, doi:10.1126/science.1072815, 2002.

Beer, C. J., Schiebel, R., and Wilson, P. A.: Technical note: On methodologies for determining the size-normalised weight of planktic Foraminifera, Biogeosciences, 7, 2193-2198, doi:10.5194/bg-7-2193-2010, 2010a.

Beer, C. J., Schiebel, R., and Wilson, P. A.: Testing planktic foraminiferal shell weight as a surface water $\left[\mathrm{CO}_{3}^{2-}\right]$ proxy using plankton net samples, Geology, 38, 103-106, doi:10.1130/G30150.1, 2010b.

Bijma, J., Spero, H. J., and Lea, D. W.: Reassessing foraminiferal stable isotope geochemistry: Impact of the oceanic carbonate system (experimental results), in: Use of Proxies in Paleoceanography: Examples from the South Atlantic, edited by: Fischer, G. and Wefer, G., 489-512, Springer-Verlag, Berlin, Heidelberg, 1999.

Bleil, U., Brück, L., Frederichs, T., Haese, R., Hensen, C., Hilgenfeldt, C., Hoek, R., Hübscher, C., von Lom-Keil, H., Janke, A., Kreutz, R., Keenan, J., Little, M. L., Martens, H., Rosiak, U., Schmidt, W., Schneider, R., Segl, M., Spieß, V., UenzelmannNeben, G., Urbanek, H., and Zühlsdorff, L.: Geo Bremen South Atlantic 1996, Meteor Berichte, Leitstelle MEteor, Hamburg, 1997.

Broecker, W. and Clark, E.: An evaluation of Lohmann's Foraminifera weight dissolution index, Paleoceanography, 16, 531-534, doi:10.1029/2000PA000600, 2001.

Cane, T., Rohling, E. J., Kemp, A. E. S., Cooke, S., and Pearce, R. B.: High-resolution stratigraphic framework for Mediterranean Sapropel S5: Defining temporal relationships between records of Eemian climate variability, Palaeogeogr. Palaeocl. Palaeoecol., 183, 87-101, doi:10.1016/S0031-0182(01)00461-8, 2002.

Chierici, M. and Fransson, A.: Calcium carbonate saturation in the surface water of the Arctic Ocean: Undersaturation in freshwater influenced shelves, Biogeosciences, 6, 2421-2432, doi:10.5194/bg-6-2421-2009, 2009.
Conover, W. J.: Practical Nonparametric Statistics, Wiley Series in Probability and Mathematical Statistics, John Wiley \& Sons, Ltd., New York, 1980.

Cramér, H.: Mathematical Methods of Statistics, vol. 9 of Princeton Mathematical Series, Princeton University Press, Princeton, 1946.

de Moel, H., Ganssen, G. M., Peeters, F. J. C., Jung, S. J. A., Kroon, D., Brummer, G. J. A., and Zeebe, R. E.: Planktic foraminiferal shell thinning in the Arabian Sea due to anthropogenic ocean acidification?, Biogeosciences, 6, 1917-1925, doi:10.5194/bg-61917-2009, 2009.

de Vargas, C., Norris, R., Zaninetti, L., Gibb, S. W., and Pawlowski, J.: Molecular evidence of cryptic speciation in planktonic foraminifers and their relation to oceanic provinces, P. Natl. Acad. Sci. USA, 96, 2864-2868, doi:10.1073/pnas.96.6.2864, 1999.

de Villiers, S.: Optimum growth conditions as opposed to calcite saturation as a control on the calcification rate and shell-weight of marine Foraminifera, Mar. Biol., 144, 45-49, doi:10.1007/s00227-003-1183-8, 2004.

Gasse, F.: Hydrological changes in the African tropics since the last glacial maximum, Quaternary Sci. Rev., 19, 189-211, doi:10.1016/S0277-3791(99)00061-X, 2000.

Hartigan, J. A. and Hartigan, P. M.: The Dip Test of unimodality, Ann. Stat., 13, 70-84, doi:10.1214/aos/1176346577, 1985.

Hayes, A., Kučera, M., Kallel, N., Sbaffi, L., and Rohling, E. J.: Glacial Mediterranean sea surface temperatures based on planktonic foraminiferal assemblages, Quaternary Sci. Rev., 24, 9991016, doi:10.1016/j.quascirev.2004.02.018, 2005.

Hayward, B. W., Sabaa, A. T., Kawagata, S., and Grenfell, H. R.: The Early Pliocene re-colonisation of the deep Mediterranean Sea by benthic Foraminifera and their pulsed Late Pliocene-Middle Pleistocene decline. Mar. Micropal., 71, 97112, doi:10.1016/j.marmicro.2009.01.008, 2009.

Helsel, D. R. and Hirsch, R. M.: Statistical methods in water resources, in: Hydrologic Analysis and Interpretation, vol. 4 of Techniques of Water-Resources Investigations Reports, chap. A3, 1-510, US Geological Survey, 2002.

Hemleben, C., Becker, T., Bellas, S., Benningsen, G., Casford, J., Cagatay, N., Emeis, K.-C., Engelen, B., Ertan, T., Fontanier, C., Friedrich, O., Frydas, D., Giunta, S., Hoffelner, H., Jorissen, F., Kahl, G., Kaszemeik, K., Lykousis, V., Meier, S., Nickel, G., Overman, J., Pross, J., Reichel, T., Robert, C., Rohling, E., Ruschmeier, W., Sakinc, M., Schiebel, R., Schmiedl, G., Schubert, K., Schulz, H., Tischnak, J., and Truscheit, T.: OstatlantikMittelmeer-Schwarzes Meer Part 3: Cruise No. 51, Leg 3, METEOR Berichte, Leitstelle METEOR, Hamburg, 2003.

Hoelzmann, P., Kruse, H.-J., and Rottinger, F.: Precipitation estimates for the eastern Saharan palaeomonsoon based on a water balance model of the West Nubian Palaeolake Basin, Global Planet. Change, 26, 105-120, doi:10.1016/S09218181(00)00038-2, 2000.

Hyndman, R. J. and Fan, Y.: Sample quantiles in statistical packages, Am. Stat., 50, 361-365, doi:10.1080/00031305.1996.10473566, 1996.

Kendall, M. G.: A new measurement of rank correlation, Biometrika, 30, 81-93, doi:10.1093/biomet/30.1-2.81, 1938.

Kučera, M., Weinelt, M., Kiefer, T., Pflaumann, U., Hayes, A., Weinelt, M., Chen, M.-T., Mix, A. C., Barrows, T. T., Cor- 
tijo, E., Duprat, J., Juggins, S., and Waelbroeck, C.: Reconstruction of sea-surface temperatures from assemblages of planktonic Foraminifera: Multi-technique approach based on geographically constrained calibration data sets and its application to glacial Atlantic and Pacific Oceans, Quaternary Sci. Rev., 24, 951-998, doi:10.1016/j.quascirev.2004.07.014, 2005.

Lohmann, G. P.: A model for variation in the chemistry of planktonic Foraminifera due to secondary calcification selective dissolution, Paleoceanography, 10, 445-457, doi:10.1029/95PA00059, 1995.

Lombard, F., da Rocha, R. E., Bijma, J., and Gattuso, J.-P.: Effect of carbonate ion concentration and irradiance on calcfication in planktonic Foraminifera, Biogeosciences, 7, 247-255, doi:10.5194/bg-7-247-2010, 2010.

Manno, C., Morata, N., and Bellerby, R.: Effect of ocean acidification and temperature increase on the planktonic foraminifer Neogloboquadrina pachyderma (sinistral), Polar Biol., 35, 1311-1319, doi:10.1007/s00300-012-1174-7, 2012.

Marino, G., Rohling, E. J., Rijpstra, W. I. C., Sangiorgi, F., Schouten, S., and Damsté, J. S. S.: Aegean Sea as driver of hydrographic and ecological changes in the Eastern Mediterranean, Geology, 35, 675-678, doi:10.1130/G23831A.1, 2007.

Marshall, B. J., Thunell, R. C., Henehan, M. H., Astor, Y., and Wejnert, K. R.: Planktonic foraminiferal area density as a proxy for carbonate ion concentration: A calibration study using the Cariaco Basin Ocean Time Series, Paleoceanography, 28, 1-14, doi:10.1002/palo.20034, 2013.

Media Cybernetics, Inc.: Image-Pro ${ }^{\circledR}$ Plus Version 6.0 for Windows ${ }^{\mathrm{TM}}$ Start-Up Guide, Silver-Spring, 2006.

Moller, T.: Formation and palaeoclimatic interpretation of a continuously laminated Sapropel $\mathrm{S}_{5}$ : A window to the climate variability during the Eemian interglacial in the Eastern Mediterranean, $\mathrm{Ph} . \mathrm{D}$. thesis, Eberhard-Karls-Universität Tübingen, Tübingen, http://nbn-resolving.de/urn:nbn:de:bsz:21-opus-63524, 2012.

Moller, T., Schulz, H., Hamann, Y., Dellwig, O., and Kučera, M.: Sedimentology and geochemistry of an exceptionally preserved last interglacial Sapropel S5 in the Levantine Basin (Mediterranean Sea), Mar. Geol., 291-294, 34-48, doi:10.1016/j.margeo.2011.10.011, 2012.

Morard, R., Quillévéré, F., Douady, C. J., de Vargas, C., de GaridelThoron, T., and Escarguel, G.: Worldwide genotyping in the planktonic foraminifer Globoconella inflata: Implications for life history and paleoceanography, PLoS ONE, 6, e26665, doi:10.1371/journal.pone.0026665, 2011.

Moy, A. D., Howard, W. R., Bray, S. G., and Trull, T. W.: Reduced calcification in modern Southern Ocean planktonic Foraminifera, Nat. Geosci., 2, 276-280, doi:10.1038/NGEO460, 2009.

Myers, P. G., Haines, K., and Rohling, E. J.: Modeling the palecocirculation of the Mediterranean: The last glacial maximum and the Holocene with emphasis on the formation of Sapropel $S_{1}$, Paleoceanography, 13, 586-606, doi:10.1029/98PA02736, 1998.

Pearson, P. N., Ditchfield, P. W., Singano, J., Harcourt-Brown, K. G., Nicholas, C. J., Olsson, R. K., Shackleton, N. J., and Hall, M. A.: Warm tropical sea surface temperatures in the Late Cretaceous and Eocene epochs, Nature, 413, 481-487, doi:10.1038/35097000, 2001.

Pujol, C. and Vergnaud Grazzini, C.: Distribution patterns of live planktic foraminifers as related to regional hydrography and pro- ductive systems of the Mediterranean Sea, Mar. Micropaleontol. 25, 187-217, doi:10.1016/0377-8398(95)00002-I, 1995.

R Development Core Team: R: A Language and Environment for Statistical Computing, R Foundation for Statistical Computing, Vienna, http://www.R-project.org/, 2011.

Rinna, J., Warning, B., Meyers, P. A., Brumsack, H.-J., and Rullkötter, J.: Combined organic and inorganic geochemical reconstruction of paleodepositional conditions of a Pliocene sapropel from the Eastern Mediterranean Sea, Geochim. Cosmochim. Ac., 66, 1969-1986, doi:10.1016/S0016-7037(02)00826-8, 2002.

Rohling, E., Abu-Zied, R., Casford, J., Hayes, A., and Hoogakker, B.: The marine environment: Present and past, in: The Physical Geography of the Mediterranean, edited by: Woodward, J., The Oxford Regional Environments Series, chap. 2, 33-67, Oxford University Press, New York, 2009.

Rohling, E. J.: Environmental control on Mediterranean salinity and $\delta^{18} \mathrm{O}$, Paleoceanography, 14, 706-715, doi:10.1029/1999PA900042, 1999.

Rohling, E. J., de Rijk, S., Myers, P. G., and Haines, K.: Palaeoceanography and numerical modelling: The Mediterranean Sea at times of sapropel formation, in: Climates: Past and Present, edited by: Hart, M. B., vol. 181 of Special Publications of the Geological Society, 135-149, Geological Society, London, doi:10.1144/GSL.SP.2000.181.01.13, 2000.

Rohling, E. J., Cane, T. R., Cooke, S., Sprovieri, M., Bouloubassi, I., Emeis, K.-C., Schiebel, R., Kroon, D., Jorissen, F. J., Lorre, A., and Kemp, A. E. S.: African monsoon variability during the previous interglacial maximum, Earth Planet. Sc. Lett., 202, 6175, doi:10.1016/S0012-821X(02)00775-6, 2002.

Rohling, E. J., Sprovieri, M., Cane, T., Casford, J. S. L., Cooke, S., Bouloubassi, I., Emeis, K.-C., Schiebel, R., Rogerson, M., Hayes, A., Jorissen, F. J., and Kroon, D.: Reconstructing past planktic foraminiferal habitats using stable isotope data: A case history for Mediterranean Sapropel S5, Mar. Micropaleontol., 50, 89-123, doi:10.1016/S0377-8398(03)00068-9, 2004.

Rossignol-Strick, M.: African monsoons, an immediate climate response to orbital insolation, Nature, 304, 46-49, doi:10.1038/304046a0, 1983.

Rossignol-Strick, M., Nesteroff, W., Olive, P., and Vergnaud Grazzini, C.: After the deluge: Mediterranean stagnation and sapropel formation, Nature, 295, 105-110, doi:10.1038/295105a0, 1982.

Schiebel, R., Waniek, J., Zeltner, A., and Alves, M.: Impact of the Azores Front on the distribution of planktic foraminifers, shelled gastropods, and coccolithophorids, Deep-Sea Res. Pt. II, 49, 4035-4050, doi:10.1016/S0967-0645(02)00141-8, 2002.

Schindelin, J., Arganda-Carreras, I., Frise, E., Kaynig, V., Longair, M., Pietzsch, T., Preibisch, S., Rueden, C., Saalfeld, S., Schmid, B., Tinevez, J.-Y., White, D. J., Hartenstein, V., Eliceiri, K., Tomancak, P., and Cardona, A.: Fiji: An open-source platform for biological-image analysis, Nat. Methods, 9, 676-682, doi:10.1038/nmeth.2019, 2012.

Schmidt, D. N., Renaud, S., Bollmann, J., Schiebel, R., and Thierstein, H. R.: Size distribution of Holocene planktic foraminifer assemblages: Biogeography, ecology and adaptation, Mar. Micropaleontol., 50, 319-338, doi:10.1016/S0377-8398(03)000987, 2004.

Schneider, A., Wallace, D. W. R., and Körtzinger, A.: Alkalinity of the Mediterranean Sea, Geophys. Res. Lett., 34, L15608, doi:10.1029/2006GL028842, 2007. 
Schulz, H., Bayer, M., Denker, C., Hemleben, C., Martínez Botí, M., Numberger, L. D., Palamenghi, L., Storz, D., and van Raden, U.: Cruise Report - Cruise No.: 334, F. S. Poseidon Cruise Reports, Leibniz-Institut für Meereswissenschaften an der Universität Kiel, Kiel, 2006.

Seiter, K., Hensen, C., and Zabel, M.: Benthic carbon mineralization on a global scale. Global Biogeochem. Cy., 19, GB1010, doi:10.1029/2004GB002225, 2005.

Sen, P. K.: Estimates of the regression coefficient based on Kendall's Tau, J. Am. Stat. Assoc., 63, 1379-1389, http://www. jstor.org/stable/2285891, 1968.

Shapiro, S. S. and Wilk, M. B.: An analysis of variance test for normality (complete samples), Biometrika, 52, 591-611, doi:10.1093/biomet/52.3-4.591, 1965.

Theil, H.: A rank-invariant method of linear and polynomial regression analysis, III, P. K. Ned. Akad. Wetensc., 53, 1397-1412, 1950.

Trask, P. D.: Relation of salinity to the calcium carbonate content of marine sediments, in: Shorter Contributions to General Geology, edited by: Ickes, H. I. and Mendenhall, W. C., vol. 186 of United States Geological Survey Professional Papers, 273-299, United States Government Printing Office, Washington, https://play.google.com/store/books/details?id= POIRAAAAIAAJ\&rdid=book-P0IRAAAAIAAJ\&rdot=1, 1937. van der Meer, M. T. J., Baas, M., Rijpstra, W. I. C., Marino, G., Rohling, E. J., Damsté, J. S. S., and Schouten, S.: Hydrogen isotopic compositions of long-chain alkenones record freshwater flooding of the Eastern Mediterranean at the onset of sapropel deposition, Earth Planet. Sc. Lett., 262, 594-600, doi:10.1016/j.eps1.2007.08.014, 2007.

van Raden, U. J., Groeneveld, J., Raitzsch, M., and Kučera, M.: $\mathrm{Mg} / \mathrm{Ca}$ in the planktonic Foraminifera Globorotalia inflata and Globigerinoides bulloides from Western Mediterranean plankton tow and core top samples, Mar. Micropaleontol., 78, 101-112, doi:10.1016/j.marmicro.2010.11.002, 2011.

Vangel, M. G.: Confidence intervals for a normal coefficient of variation, Am. Stat., 50, 21-26, http://www.jstor.org/stable/2685039, 1996.

Williams, D. F., Thunell, R. C., and Kennett, J. P.: Periodic freshwater flooding and stagnation of the Eastern Mediterranean Sea during the late Quaternary, Science, 201, 252-254, doi:10.1126/science.201.4352.252, 1978.

Wüst, G.: On the vertical circulation of the Mediterranean Sea, J. Geophys. Res., 66, 3261-3271, doi:10.1029/JZ066i010p03261, 1961.

Yates, F.: Contingency tables involving small numbers and the $\chi^{2}$ Test, J. Roy. Stat. Soc. Supp., 1, 217-235, http://www.jstor.org/ stable/2983604, 1934. 